\title{
Factors Associated with Adult Mental Health Treatment Among Youth with and without Adverse Childhood Experiences from the 1997 National Longitudinal Survey of Youth
}

Teal W. Benevides ( $\nabla$ teal.benevides@gmail.com )

Augusta University https://orcid.org/0000-0003-1395-2628

Vahe Heboyan

Augusta University

Ashwini Tiwari

Augusta University

Megan Douglas

Morehouse School of Medicine

Research article

Keywords: Mental Health, Adverse Childhood Experiences, Life Course Outcomes, longitudinal, National Longitudinal Survey of Youth 1997 (NLSY97)

Posted Date: August 26th, 2020

DOI: https://doi.org/10.21203/rs.3.rs-59695/v1

License: (c) (1) This work is licensed under a Creative Commons Attribution 4.0 International License.

Read Full License 
4

RUNNING HEAD: LONGITUDINAL MENTAL HEALTH

Factors Associated with Adult Mental Health Treatment Among Youth with and without Adverse Childhood Experiences from the 1997 National Longitudinal Survey of Youth

Teal W. Benevides, PhD, MS, OTR/L

Vahé Heboyan, $\mathrm{PhD}$

Ashwini Tiwari, PhD

Megan Douglas, JD

Teal Benevides, PhD, Associate Professor, Department of Occupational Therapy, College of Allied Health Sciences and Associate Professor, Institute of Public and Preventative Health, Augusta University

Vahé Heboyan, PhD, Assistant Professor, Department of Interdisciplinary Research, College of Allied Health Sciences, Augusta University

Ashwini Tiwari, PhD, Assistant Professor, Institute of Public \& Preventive Health, Augusta University

Megan Douglas, JD, Assistant Professor, Department of Community Health \& Preventive Medicine; Policy Director, National Center for Primary Care; and Associate Director for Policy, Kennedy-Satcher Center for Mental Health Equity, Morehouse School of Medicine

Presentation information: This study was presented as a poster at the AcademyHealth Annual Research Meeting, virtual due to COVID-19, summer 2020.

Corresponding Author: Teal W. Benevides, PhD, OTR/L, 987 St. Sebastian Way, EC-2324, Augusta, Georgia, 30912; tbenevides@augusta.edu, 1-706-446-0003 


\section{Abstract}

2 Background: Evidence suggests that childhood is an important critical period for adult mental

3 health outcomes. Most studies evaluating childhood factors use cross-sectional data, limiting our

4 understanding of life course factors contributing to mental health. The purpose of this study was

5 to evaluate the contribution of life course factors on adult mental health treatment from a

6 longitudinal cohort of U.S. respondents.

7 Methods: We used data from the National Longitudinal Survey of Youth-1997 $(\mathrm{N}=8,984)$

8 through the 2011 data collection year, in which $n=7,009$ adult respondents reported on the

9 number of mental health visits between 2009-2011. We used zero-inflated negative binomial

10 regression to evaluate the impact of childhood, adolescent, and adult factors on mental health

11 visits.

12 Results: Respondents with more than three adverse childhood experiences (ACE) reported in

13 adolescence were significantly more likely to utilize mental health treatment as an adult

14 (Incidence Rate Ratio[IRR]=1.30). No other childhood or adolescent factors contributed to adult

15 mental health utilization. Adult factors associated with greater mental health visits included:

16 having any health insurance (IRR=1.40), being unemployed (IRR=1.56) or employed part-time

17 (IRR=1.31). African-American respondents had significantly fewer mental health visits than

18 white respondents (IRR=0.79). Non-significant factors included: gender, ethnicity, parent-

19 reported childhood emotional problem, family receipt of governmental assistance as an

20 adolescent, living in a high-poverty household as an adult, and living in a state with high

21 unemployment.

22 Conclusions: Critical periods of development, combined with cumulative risk and protective

23 factors, contribute to adult mental health seeking. Adolescence is a critical period for trauma and 
1 later need for mental health treatment. Other factors, such as full-time employment, appear to be

2 associated with reduced likelihood of the need for mental health treatment. Future evaluation of

3 community and population-based approaches, including policy interventions, is needed to

4 understand risk and protective factors contributing to mental health across the life course.

5 Key Words: Mental Health, Adverse Childhood Experiences, Life Course Outcomes,

6 longitudinal, National Longitudinal Survey of Youth 1997 (NLSY97) 
1

\section{Background}

Between 20 to $40 \%$ of adolescents have a lifetime prevalence of a mental health (MH) condition.(1) Improving adolescent $\mathrm{MH}$ and treatment is a national priority for achieving public health. Healthy People 2020 recognizes 12 long-term priorities to improve MH outcomes in the United States, with 50\% of the goals related to improving mental health outcomes among youth under the age of 18 years.(2) Similarly, the U.S. Health Resources and Services Administration, Maternal and Child Health Bureau [4] has prioritized two National Outcome Measures associated with mental health: obtaining mental health treatment (NOM-18), and reducing suicide among adolescents (NOM-16.3). National Outcome Measures reflect longer-term metrics that demonstrate successful maternal and child health initiatives of state Title V programs and state governments.(3) Addressing mental health and the factors that contribute to poor mental health, are of critical public health importance.

Improving $\mathrm{MH}$ requires prevention efforts to target life course experiences that impact an individual's MH trajectory. Halfon and Hochstein(4) proposed that early interactions of a child with his or her environment, along with other biological and social factors, could alter trajectories of health. Their Life Course Health Development framework has been adopted by the Maternal and Child Health Bureau(5) and the World Health Organization(6) as a model for understanding necessary biological, social, temporal, and psychological factors that influence later-life health. Since that time, life course outcomes research has demonstrated that a variety of risk and protective factors at the individual, family, and environmental levels intersect to promote or hinder health outcomes.(7-9) Evidence from large longitudinal studies, for example, 2 suggests that early socioeconomic indicators predict adult health outcomes. $(10,11)$ 
Factors that intersect to promote positive or negative health over a person's lifetime are of utmost interest to public health and medical practitioners. However, most literature evaluates the impact of early risk and protective factors on physical health outcomes, such as cardiovascular events(12), diabetes(13), or obesity(14), to the exclusion of MH outcomes. As such, any recommendations for preventive health focus on approaches and strategies to reduce long-term cardiovascular risk, such as healthy diet and exercise. There is a paucity of research evaluating the impact of life course factors evaluated over long periods of a person's life on $\mathrm{MH}$ outcomes.

Recent evidence from a high-quality meta-analysis suggests that adverse child and adolescent experiences (ACE) are strong predictors of future MH.(15) Taken across the lifespan, poverty, exposure to violence and abuse, separation from family, homelessness, and insufficient health insurance contribute to greater risk for $\mathrm{MH}$ problems in adulthood.(15, 16) Unfortunately, although rigorous research supports the impact of ACE and other adversity on outcomes in crosssectional analyses (17), few studies evaluate individuals over time, $(13,18)$ hampering public health efforts to understand and develop systematic risk reduction approaches for those on trajectories of poor $\mathrm{MH}$ across critical periods.

The life course approach to epidemiological evaluation of health suggests life outcomes are impacted by earlier life experiences.(6) Halfon and colleagues(4) suggested that both risk and protective factors, in conjunction with critical periods of development, set individuals on optimal or poor trajectories for later adult health. One challenge to testing these hypotheses is the nature of examining such trajectories necessarily requires longitudinal (not cross-sectional) data. Our study specifically relies on longitudinal data to investigate the combined premise that early risk for $\mathrm{MH}$ problems predicts later life outcomes, but that later life protective or risk factors will 
1 more strongly contribute to adult MH than early life factors. We hypothesized that youth

2 reported to have an emotional or learning problem at Time 1 in 1997 will demonstrate

3 statistically different self-reported MH treatment in adulthood between 2009-2011 than those not

4 reported to have early life emotional or learning problems (H1-Critical Period Hypothesis). We

5 also hypothesized that individual factors in adulthood will be more strongly associated with adult

$6 \mathrm{MH}$ treatment than individual, family, or environmental factors measured at earlier periods of

7 time (H2- Critical Period Plus Later Life Modifiers).

8 Methods

9 Design

We used a retrospective longitudinal design of existing secondary data, with individual,

11 family, and environmental variables measured at three points: T1 (late childhood or early

12 adolescence), T3-T10 (adolescent period), and as an adult in 2009 (T13), 2010 (T14), and 2011

13 (T15). This study was deemed non-human subjects research following Institutional Review

14 Board review at the primary author's institution.

\section{Data Sources and Sampling}

We used secondary data from rounds 1-15 of the National Longitudinal Survey for Youth

171997 (NLSY97).(19) The NLSY97 survey is funded by the U.S. Bureau of Labor Statistics

18 (BLS). The NLSY97 includes a nationally representative sample of youth who were 12 to 16

19 years of age as of December 31, 1996. A national representation of youth of various

20 demographic characteristics and a large sample size $(\mathrm{N}=8,984)$ support statistical power

21 sufficient to detect even small associations. Details regarding the panel data collection and

22 sampling is publicly-available.(19) We used the entire available sample for analysis at each time 
1 point, thus no inclusion/exclusion criteria were applied. In order to link participants to state-level

2 unemployment rates, we also use a restricted-access BLS state geocode.

\section{$3 \quad$ Variables}

4

5

Outcome Variable. Our primary outcome was self-reported adult mental health treatment at T13-15, when respondents were between 23-30 years old: "How many times have you been treated by a mental health professional?' Data were coded as either '0' visits, '1', '2', '3', or '4 or more' visits in a year. MH treatment was treated as both a binary variable (any MH treatment-Y/N) and as a count variable (total number of visits). The count variable was rightcensored. The sum total of visits in the three-year period therefore ranged from 0-12 visits. Predictor Variables. Risk and protective factors were those occurring during the late childhood period (T1), adolescent period (between T3-T10), or adult period (T13-T15). Not all questions were asked for each timepoint, therefore, our selected variables reflect both theoretically selected and pragmatically available variables. Risk factors contributed to an increased likelihood of MH problems (e.g. increase need) and/or lack of resources to obtain $\mathrm{MH}$ treatment for perceived problems (e.g. reduced opportunity to address need). Protective factors contributed to an individual's ability to reduce their MH risk (e.g. reduce need), and/or provided resources that help the individual address their MH problems (e.g. increased opportunity to address need). In our model, selected childhood risk factors included: having an emotional/learning problem at $\mathrm{T} 1$ and being female. The adolescent risk factors included: greater ACEs, and the respondent's family being on welfare at any point in the adolescent period. The adult risk factors were lack of health insurance, unemployment, self-report of poor/fair/good health (as compared 
1 to very good/excellent health), living in a household with income at $<300 \%$ federal poverty level

2 (FPL), and living in a state with $>7.5 \%$ unemployment in 2009.

(Table 1). This variable was used as a categorical variable with four levels $(0,1,2$, or $3+\mathrm{ACE})$.

Table 1. Adverse Childhood Experiences Ascertained in NLSY97 Survey Waves between 199782002

1. Is Youth's first non-responding biological parent deceased?

2. Is Youth's second non-responding biological parent deceased?

3 . In the last 5 years, since you were $x$ years old, has a close relative of yours died?

4. In the last 5 years, has an adult member of your household other than yourself experienced one or more periods of unemployment lasting at least 6 months?

5. In the last 5 years, have your parents divorced, either from each other or from their former spouse?

6. In the last 5 years, has an adult member of your household other than yourself been sent to jail or prison?

7. In the last 5 years, have you been the victim of a violent crime for example, physical or sexual assault, robbery or arson?

8. Sometimes children go through hard times. For example, they live in a place without water or electricity, or in a homeless shelter. To the best of your knowledge, has [this youth] ever experienced such hard times?

9. Before you turned age 12 , were you ever the victim of repeated bullying?

10. Did you ever have your house or apartment broken into between the ages of 12-18?

11. Between ages of 12-19, have you ever been shot at or seen someone get shot or shot at with a gun? years' questions were specifically referencing the period between 1997-2002.

\section{Statistical Analyses} design features and years used for analysis.(20) Stata's svyset function was used for weighting: strata (VSTRAT_1997), sampling unit (VPSU_1997), and a sampling weight (pweight). Per the 
Missingness and Power. A total of 8,984 respondents participated in T1 NLSY97 questions. Of these, 7,880 respondents answered whether they had an emotional or learning problem at T1. At Time 13-15, a maximum of 7,009 respondents provided answers on all variables used in our analyses. No corrections were made for missingness. An a priori power analysis was conducted for both the bivariate and multivariate tests; we had more than the $n=964$ minimum sample to detect medium effect sizes for both hypotheses.(21)

Primary Analyses. We used weighted design-based F statistics to test the null hypothesis of no difference in the reported proportion of adults reporting any MH treatment for each year $(\mathrm{T} 13,14,15)$ for those with a parent-reported emotional or learning problem at T1 (Hyp 1). We used zero-inflated negative binomial regression (ZINB) to evaluate the contribution of life course variables on number of adult MH visits (Hyp 2). We considered the use of zero-inflated Poisson regression, however, based on statistically significant Vuong test(22), and evaluation of AIC and $\mathrm{BIC}(23)$, the best estimation approach was ZINB. The regression was inflated on all predictors, with stepwise reduction of the inflated model to include only statistically significant predictors resulting in good overall model fit (log-alpha $<0.05)$. Only the count model, predicting MH visits greater than 0 , is presented. Alpha was set to $p<.05$ for all analyses.

\section{Results}

In 1997 (T1), 7,880 parents of youth aged 12-16 years provided data on whether the youth had an emotional problem (Table 2). Approximately $10 \%$ were reported to have an emotional or learning problem. Those with emotional problems were statistically more likely than those with no emotional problem to: report Fair or Poor health in childhood; receive welfare during adolescence; have three or more ACEs; and were less likely to be employed full time or have health insurance in adulthood. 
1 Table 2. Weighted Individual, Family, and Environmental Characteristics of Respondents with

2 reported Emotional Problems at Time 1

\begin{tabular}{|c|c|c|c|}
\hline & $\begin{array}{c}\text { No Emotional } \\
\text { Problem } \\
(\mathbf{n}=7,058)\end{array}$ & $\begin{array}{c}\text { Yes Emotional } \\
\text { Problem } \\
(\mathbf{n}=822)\end{array}$ & $\begin{array}{c}\text { Total } \\
\text { respondents } \\
(\mathrm{N}=7,880)\end{array}$ \\
\hline $\begin{array}{l}\text { Individual Factors } \\
f(\text { weighted \%) }\end{array}$ & & & \\
\hline $\begin{array}{l}\text { Age in Years, Mean (SD) } \\
\text { Sex }\end{array}$ & $14.30(1.47)$ & $14.18(1.49)$ & $14.29(1.47)$ \\
\hline $\begin{array}{l}\text { Female } \\
\text { Hispanic status }\end{array}$ & $3,553(50.68)$ & $281(34.63)$ & $3,834(48.88)$ \\
\hline Race ${ }^{\text {Hispanic }}$ & $1,461(12.68)$ & $118(9.11)$ & $1,579(12.28)$ \\
\hline $\begin{array}{l}\text { White } \\
\text { African-American } \\
\text { Other } \\
\text { Missing }\end{array}$ & $\begin{array}{c}4,163(73.42) \\
1,887(15.76) \\
963(10.44) \\
45(3.8)\end{array}$ & $\begin{array}{c}531(78.80) \\
208(13.89) \\
80(6.81) \\
3(0.50)\end{array}$ & $\begin{array}{l}4,694(74.02) \\
2,095(15.55) \\
1,043(10.03) \\
\quad 48(3.9)\end{array}$ \\
\hline $\begin{array}{l}\text { Adverse Childhood Events, 1997-2002 } \\
\quad 0 \\
\quad 1 \\
\quad 2 \\
\quad>3\end{array}$ & $\begin{array}{l}1,395(22.76) \\
2,392(38.34) \\
2,027(24.19) \\
1,244(14.71)\end{array}$ & $\begin{array}{l}99(12.57) \\
263(35.46) \\
229(26.38) \\
231(25.59)\end{array}$ & $\begin{array}{l}1,494(21.62) \\
2,655(38.02) \\
2,256(24.44) \\
1,475(15.93)\end{array}$ \\
\hline $\begin{array}{l}\text { General Health, } 2009 \\
\text { Excellent } \\
\text { Very Good } \\
\text { Good } \\
\text { Fair/Poor } \\
\text { Missing }\end{array}$ & $\begin{array}{c}1,442(24.46) \\
2,289(40.23) \\
1,677(27.05) \\
570(8.23) \\
1,080(0.034)\end{array}$ & $\begin{array}{l}135(16.30) \\
212(31.76) \\
235(33.98) \\
124(17.96) \\
116(0.0)\end{array}$ & $\begin{array}{l}1,577(23.54) \\
2,501(39.28) \\
1,912(27.83) \\
694(9.32) \\
1,196(0.03)\end{array}$ \\
\hline $\begin{array}{l}\text { Health Insurance Status } 2009 \\
\text { Uninsured } \\
\text { Insured } \\
\text { Missing }\end{array}$ & $\begin{array}{c}1,921(29.22) \\
4,053(70.73) \\
1,084(0.52)\end{array}$ & $\begin{array}{c}309(42.57) \\
396(57.14) \\
117(0.29)\end{array}$ & $\begin{array}{c}2,230(30.72) \\
4,449(69.20) \\
1,201(0.79)\end{array}$ \\
\hline $\begin{array}{l}\text { Employment, } 2009 \\
\text { None } \\
\text { Part-time } \\
\text { Full-time } \\
\text { Missing }\end{array}$ & $\begin{array}{l}1,186(16.65) \\
1,618(24.66) \\
3,463(56.39) \\
791(2.29)\end{array}$ & $\begin{array}{l}216(24.80) \\
200(27.41) \\
316(43.98) \\
90(3.82)\end{array}$ & $\begin{array}{c}1,402(17.56) \\
1,818(24.97) \\
3,779(55.00) \\
881(2.47)\end{array}$ \\
\hline $\begin{array}{l}\text { Poverty Ratio, } 2009 \\
\text { 0-99\% FPL } \\
\text { 100-199\% FPL } \\
\text { 200-299\% FPL } \\
\text { 300\% and over FPL } \\
\text { Missing }\end{array}$ & $\begin{array}{c}915(11.64) \\
982(15.89) \\
939(16.28) \\
2,460(45.88) \\
1,762(10.31)\end{array}$ & $\begin{array}{l}192(22.29) \\
118(17.63) \\
89(14.38) \\
211(32.63) \\
212(13.08)\end{array}$ & $\begin{array}{l}1,107(12.83) \\
1,100(16.09) \\
1,028(16.07) \\
2,671(44.40) \\
1,974(10.62)\end{array}$ \\
\hline Family Factor & & & \\
\hline $\begin{array}{l}\text { Any government assistance, 2005-2009 } \\
\text { Environmental Factor }\end{array}$ & $2,134(29.02)$ & $320(40.88)$ & $2,454(30.35)$ \\
\hline $\begin{array}{l}\text { State Unemployment Rate, } 2009 \\
\text { 4-7.5\% } \\
\text { Over 7.5\% } \\
\text { Missing }\end{array}$ & $\begin{array}{c}703(12.62) \\
5,114(84.79) \\
1,241(2.59)\end{array}$ & $\begin{array}{c}94(14.09) \\
605(84.53) \\
123(1.38) \\
\end{array}$ & $\begin{array}{c}797(12.79) \\
5,719(84.76) \\
1,364(2.46)\end{array}$ \\
\hline
\end{tabular}


In our analysis of primary hypotheses, we found that those with parent-reported

emotional problems were significantly more likely to report any MH treatment in adulthood at each time point: $2009(F(1,117)=12.01, p=.0007), 2010(F(1,117)=13.19, p=.0004)$, and 2011 $(F(1,117)=20.99, p<.0001)($ Table 3$)$.

8 adults were significantly less likely to report MH visits than white respondents.

Table 3. Weighted percentage of respondents with emotional problem in 1997 accessing mental health treatment in 2009-2011

\section{Respondents Reporting Receipt of 1 or More Mental Health Visits} (\%) [95\% Confidence Interval]

\begin{tabular}{ccc}
\hline & No Emotional Problem & Yes Emotional Problem \\
\hline \multirow{2}{*}{$\mathbf{0 0 9 *}^{*}$} & 6.9 & 10.6 \\
$\mathbf{2 0 1 0}^{*}$ & {$[6.20,7.67]$} & {$[8.25,13.43]$} \\
& 5.2 & 10.1 \\
$\mathbf{2 0 1 1}^{*}$ & {$[4.56,5.98]$} & {$[7.31,13.85]$} \\
& 4.8 & 10.0 \\
& {$[4.19,5.51]$} & {$[7.42,13.22]$} \\
\hline
\end{tabular}

* Design-based F $(1,117)$ comparing MH visit $(0,1+)$ between those with and without emotional problems was statistically significant at $\mathrm{p}<.001$ for all comparison years, weighted using complex survey design features from the NLSY97.

Data Source: NLSY97, U.S. Bureau of Labor Statistics. 
Table 4. Life Course Factors Associated with Adult Mental Health Treatment

\begin{tabular}{|c|c|c|}
\hline & IRR $^{\mathrm{a}}$ & $95 \% \mathrm{CI}$ \\
\hline \multicolumn{3}{|l|}{ Individual Factors } \\
\hline Age & $1.05^{*}$ & $1.00-1.10$ \\
\hline \multicolumn{3}{|l|}{ Gender } \\
\hline Female & 0.93 & $0.80-1.07$ \\
\hline \multicolumn{3}{|l|}{ Race } \\
\hline Black or African-American & $0.79 * *$ & $0.65-0.94$ \\
\hline Other & 1.02 & $0.78-1.33$ \\
\hline Not reported & 1.59 & $0.58-4.57$ \\
\hline Hispanic ethnicity & 0.86 & $0.68-1.09$ \\
\hline \multicolumn{3}{|l|}{ Late Childhood } \\
\hline Yes, Emotional Problem, 1997 & 1.01 & $0.83-1.21$ \\
\hline \multicolumn{3}{|l|}{ Adolescence } \\
\hline \multicolumn{3}{|l|}{ Adverse Childhood Experiences, 1997-2002 } \\
\hline $1 \mathrm{ACE}$ & 1.14 & $0.93-1.42$ \\
\hline 2 ACEs & 1.20 & $0.96-1.50$ \\
\hline $3+$ ACEs & $1.30^{*}$ & $1.03-1.64$ \\
\hline Any government assistance as an adolescent, 2005-2009 & 0.91 & $0.77-1.07$ \\
\hline \multicolumn{3}{|l|}{ Adulthood } \\
\hline \multicolumn{3}{|l|}{ General Health, 2009} \\
\hline Good & $1.18^{*}$ & $1.01-1.38$ \\
\hline Fair or Poor & 1.09 & $0.90-1.33$ \\
\hline Has Health Insurance, 2009 & $1.40 * *$ & $1.18-1.66$ \\
\hline \multicolumn{3}{|l|}{ Employment Status, 2009} \\
\hline Unemployed & $1.56 * *$ & $1.27-1.91$ \\
\hline Part-time $(<30$ hours/week $)$ & $1.31 * *$ & $1.10-1.57$ \\
\hline \multicolumn{3}{|l|}{ Family Factors } \\
\hline \multicolumn{3}{|l|}{ Federal Poverty Level, 2009} \\
\hline $0-99 \%$ & 1.03 & $0.84-1.27$ \\
\hline $100-199 \%$ & 0.95 & $0.77-1.17$ \\
\hline $200-299 \%$ & $0.76^{* *}$ & $0.60-0.95$ \\
\hline \multicolumn{3}{|l|}{ Environmental Factors } \\
\hline \multicolumn{3}{|l|}{ Average Unemployment Rate (\%) in Residential State, 2009} \\
\hline $5.0-7.5$ & 1.10 & $0.58-2.13$ \\
\hline$>7.5$ & 0.96 & $0.51-1.81$ \\
\hline
\end{tabular}

Data Source: NLSY97, U.S. Bureau of Labor Statistics.

Abbreviations: ACE: Adverse Childhood Experience; FPL: Federal Poverty Level; IRR: Incident-rate ratio Reference case was: male, White, non-Hispanic, No emotional or learning problem, zero ACE, no government assistance, 'Excellent or very good' health, Uninsured, Employed, $>300 \%$ FPL, 0-5\% state unemployment. aZero-inflated negative binomial regression used for count dependent variable. Non-zero observations $=715$ included in count model. Zero observations=6,294; inflated on: gender, race, emotional problem as child, ACE as an adolescent, any government assistance as adolescent, health insurance status as adult, general health as adult. Inflated model results not presented.

$* p<.05, * * p<.01$ 
1

\section{Discussion}

Our population-based study measured the association of individual, family, and environmental risk factors, documented across several developmental periods, on receipt of $\mathrm{MH}$ treatment in adulthood. According to the Life Course Outcomes Model,(4) critical periods of development, combined with cumulative risk and protective factors, contribute to adult outcomes. In evaluation of a critical-period hypothesis, we found that early life emotional problems (reported by parents) was associated with greater MH treatment as an adult (as reported by grown children). Although our findings suggest a critical period for $\mathrm{MH}$ when childhood factors are evaluated in isolation, that variable-- childhood reported emotional problem-- was no longer a significant predictor of adult $\mathrm{MH}$ treatment once other adolescent and adult factors were included in our analyses.

Including later life risk and protective factors across adolescence and adulthood in additional modeling resulted in revised interpretations of the impact of childhood factors. Our second hypothesis was that adult factors would be most associated with adult MH treatment, but we did not find this to be the case entirely. Although most of the variables that predicted adult MH service use were those collected when the respondent was an adult, we found that earlier life experiences, such as reporting three or more ACEs in adolescence, contributed to a significantly greater likelihood of $\mathrm{MH}$ utilization as an adult.

Our results align with previously published literature detailing associations between exposure to ACEs and increases in broad health care utilization.(24-26) However, this is the first study to our knowledge revealing that ACEs occurring specifically in adolescence may contribute to increased reported $\mathrm{MH}$ visits seen among those same adults evaluated more than a decade later. It is well known that exposure to early adversity in childhood is a significant public 
1 health problem linked to toxic stress responses.(27) Others have also identified that among those

2 with poor $\mathrm{MH}$, the trajectories differentiating high versus lower risk groups begins in

3 adolescence, with poor outcomes manifesting in young adulthood.(8) Of interest is that once

4 adolescent ACEs were considered in our model, the earlier childhood parent-reported emotional

5 problems were no longer significant predictors of later $\mathrm{MH}$ utilization. Our data specifically

6 suggest that adolescence, perhaps more so than childhood, is a critical period for which we

7 should evaluate risk and exposure to adversity in order to prevent future metal health problems.

8 Our findings support the hypothesis that complex interactions of risk and protection,

9 occurring over a person's life, influence MH service utilization. Although our outcome was MH

10 service utilization, and not MH symptoms, well-established links between early adversity and

11 adult mental illness (15) support the idea that $\mathrm{MH}$ symptomology due to a variety of factors is

12 associated with increased service utilization. Although our study was not designed to evaluate

13 the complex social and cultural factors influencing service utilization, our finding that African

14 American participants were less likely to receive MH treatment as adults is supported by

15 literature. The complexity of cultural beliefs and stigma influence perceived need for $\mathrm{MH}$

16 treatment and realized access (obtaining needed treatment).(28, 29) More research is needed to

17 evaluate the mediating role of $\mathrm{MH}$ symptomology, and the influence of other co-occurring

18 cultural factors related to adolescent ACEs on MH-seeking behaviors in adulthood.

Of interest is that we did identify that certain adult factors were associated with greater

$20 \mathrm{MH}$ utilization, but the interpretation of these factors is ambiguous. For example, we found that

21 those who were employed full-time as an adult were statistically less likely to report MH visits

22 than those who were unemployed or underemployed. Full-time employment, therefore, appears

23 to be a protective factor, possibly acting to both reduce the need for MH treatment (e.g. 
1 accomplishment of a major developmental goal, employment, of adulthood), and providing

2 resources to address any need they might have (e.g. through financial security to pay for such

3 services). Alternatively, it could be that those who had more $\mathrm{MH}$ problems were less likely to

4 work, either due to their $\mathrm{MH}$ condition or due to stigma associated with significant mental

5 illness. Our study, however, is not able to establish a causal relationship between employment

6 status and MH utilization. Further, although we examined emotional problems in childhood,

7 many $\mathrm{MH}$ conditions emerge in early adulthood. These data were unavailable in the dataset and

8 could not be included in analyses.

9 Interestingly, having any health insurance as an adult was associated with greater $\mathrm{MH}$

10 utilization. This finding suggests, similar to the financial security argument above, that having

11 insurance is protective (e.g. increases a person's opportunity to address a MH need), despite

12 most $\mathrm{MH}$ providers not accepting insurance. Unfortunately, the variable does not distinguish

13 between those publicly insured (e.g. Medicaid) versus those privately insured.

Limitations. We acknowledge that we did not have an evaluation of diagnosed conditions,

15 which result in specific emotional or learning problems in childhood. Additionally, our models

16 relied on censored data related to our primary outcome variable ( $\mathrm{MH}$ visit counts), which could

17 have impacted our ability to understand the relationship between the variables. Of importance,

18 our definition of ACEs was limited to the constraints of the NLSY97 survey battery. Our analyses did not examine the independent effects of each type of ACE on adult MH service

20 utility - we only evaluated the accumulation of ACEs. Understanding the effect of specific types

21 of ACEs is an important next step, with recent studies highlighting that child abuse, bullying,

22 witnessing violence, caregiver death, are associated with increased utility of MH services

23 among.(30, 31) We were also unable to assess child abuse and neglect occurrences among 
1 participants. We would expect only stronger support for links between ACEs and health seeking

2 in adulthood with the inclusion of such variables. Lastly, we were unable to control for the

3 historical effects that affect a single, large cohort. Our primary outcome variable of interest, $\mathrm{MH}$

4 visits, was measured between 2009-2011, at the height of the U.S. Great Recession,(32) and

5 therefore, our results should be taken in historical context of the economic reality of the time.

6 However, we did control for state-level unemployment to address systemic or state-level effects

7 that could affect $\mathrm{MH}$.

Strengths of this study include the use of a large, longitudinal sample of youth for which

9 we have both parent report and self-report of important variables. Our results are generalizable to

10 individuals living in the United States who were born between 1980 and 1985. Our analyses rely

11 on inclusion of specific variables hypothesized to affect the outcome of interest, and future

12 analyses can continue to examine this sample's outcomes relative to earlier reported health and

13 socio-demographic experiences.

\section{Conclusions}

Novel approaches for identification of life course factors contributing to lifetime risk for

$16 \mathrm{MH}$ problems are needed to inform policy and practice interventions that provide supports

17 during critical periods of development, and for those exposed to risk factors that impact $\mathrm{MH}$

18 across their lifetime. Importantly, our results suggest that adults who are seeking greater $\mathrm{MH}$

19 treatment are significantly more likely to have had adolescent ACEs. These findings support

20 ongoing preventive efforts to identify and support children at risk for emotional problems, in

21 addition to the provision of trauma-informed care to children and adolescents who have

22 experienced or are at risk for ACEs (33). Our findings point to the need to evaluate policy efforts

23 aimed at maintaining funding for public programs that support the healthy development of 
children and adolescents, especially those most at risk for mental illness and in need of treatment at an early age. Preventive efforts to address MH throughout the life course will have the greatest public health implications for national expenditures on healthcare, and require further evaluation to determine their impact.

\section{References}

1. Merikangas KR, He JP, Burstein M, Swanson SA, Avenevoli S, Cui L, et al. Lifetime prevalence of mental disorders in U.S. adolescents: results from the National Comorbidity Survey Replication--Adolescent Supplement (NCS-A). J Am Acad Child Adolesc Psychiatry. 2010;49(10):980-9.

2. Office of Disease Prevention and Health Promotion USDoHaHS. Mental health and mental disorders 2018 [Available from: https://www.healthypeople.gov/2020/topicsobjectives/topic/mental-health-and-mental-disorders.

3. Maternal and Child Health Bureau HRaSA, U.S. Department of Health and Human Services. Title V Maternal and Child Health Services Block Grant Program [Available from: https://mchb.hrsa.gov/maternal-child-health-initiatives/title-v-maternal-and-child-healthservices-block-grant-program.

4. Halfon N, Hochstein M. Life course health development: an integrated framework for developing health, policy, and research. The Milbank quarterly. 2002;80(3):433-79, iii.

5. Maternal and Child Health Bureau HRaSA, U.S. Department of Health and Human Services. Life course approach in Maternal and Child Health. 2010 [Available from: https://mchb.hrsa.gov/training/lifecourse.asp.

6. Organization WH. The implications for training of embracing a life course approach to health [brochure].

7. Hale DR, Fitzgerald-Yau N, Viner RM. A systematic review of effective interventions for reducing multiple health risk behaviors in adolescence. American journal of public health. 2014;104(5):e19-41.

8. Seguin M, Beauchamp G, Robert M, DiMambro M, Turecki G. Developmental model of suicide trajectories. The British journal of psychiatry : the journal of mental science. 2014;205(2):120-6.

9. Szilagyi M, Halfon N. Pediatric Adverse Childhood Experiences: Implications for Life Course Health Trajectories. Academic pediatrics. 2015;15(5):467-8.

10. Hamad R, Rehkopf, D.H., Huan, K.Y, \& Cullen, M.R., . Predicting later life health status and mortality using state-level socioeconomic characteristics in early life. SSM-Population Health. 2016;2:269-76.

11. Poulton R, Caspi, A., Milne, B.J., Thomson, W.M., Taylor, A., Sears, M.R., \& Moffitt, T.E. . Association between children's experience of socioeconomic disadvantage and adult health: a life-course study. Lancet. 2002;360:1640-5.

12. Kjollesdal MKR, Ariansen I, Mortensen LH, Davey Smith G, Naess O. Educational differences in cardiovascular mortality: The role of shared family factors and cardiovascular risk factors. Scand J Public Health. 2016;44(8):744-50. 
13. Lown EA, Lui CK, Karriker-Jaffe K, Mulia N, Williams E, Ye Y, et al. Adverse childhood events and risk of diabetes onset in the 1979 National longitudinal survey of youth cohort. BMC Public Health. 2019;19(1):1007.

14. Newton S, Braithwaite D, Akinyemiju TF. Socio-economic status over the life course and obesity: Systematic review and meta-analysis. PloS one. 2017;12(5):e0177151.

15. Hughes K, Bellis MA, Hardcastle KA, Sethi D, Butchart A, Mikton C, et al. The effect of multiple adverse childhood experiences on health: a systematic review and meta-analysis. The Lancet Public health. 2017;2(8):e356-e66.

16. Najman JM, Hayatbakhsh MR, Clavarino A, Bor W, O'Callaghan MJ, Williams GM. Family poverty over the early life course and recurrent adolescent and young adult anxiety and depression: a longitudinal study. American journal of public health. 2010;100(9):1719-23.

17. Hughes K, Lowey H, Quigg Z, Bellis MA. Relationships between adverse childhood experiences and adult mental well-being: results from an English national household survey. BMC Public Health. 2016;16:222.

18. Schilling EA, Aseltine RH, Jr., Gore S. Adverse childhood experiences and mental health in young adults: a longitudinal survey. BMC Public Health. 2007;7:30.

19. Bureau of Labor Statistics USDoL. National Longitudinal Survey of Youth 1997 cohort, 1997-2017 (rounds 1-18). Produced and distributed by the Center for Human Resource Research (CHRR), The Ohio State University. Columbus, OH. [Available from: https://www.nlsinfo.org/. 20. Bureau of Labor Statistics USDoL. National Longitudinal Survey of Youth 1997, Documentation on Using and Understanding the Data, Sample weights and design effects. 2017 [Available from: https://www.nlsinfo.org/content/cohorts/nlsy97/using-and-understanding-thedata/sample-weights-design-effects.

21. Faul F, Erdfelder, E., Lang, AG., Buchner, A. G*Power 3: A flexible statistical power analysis program for the social, behavioral, and biomedical sciences. Behavior Research Methods. 2007;39:175-91.

22. Vuong QH. Likelihood Ratio Tests for Model Selection and Non-Nested Hypotheses. Econometrica. 1989;57(2):307-33.

23. Burnham KP, Anderson DR. Multimodel Inference: Understanding AIC and BIC in Model Selection. Sociological Methods \& Research. 2004;33(2):261-304.

24. Karatekin C. Adverse Childhood Experiences (ACEs), Stress and Mental Health in College Students. Stress Health. 2018;34(1):36-45.

25. Chartier MJ, Walker, J. R., \& Naimark, B. . Childhood abuse, adult health, and health care utilization: results from a representative community sample. American journal of Epidemiology. 2007;165(9):1031-8.

26. Chartier MJ, Walker, J. R., \& Naimark, B. Separate and cumulative effects of adverse childhood experiences in predicting adult health and health care utilization. Child abuse \& neglect. 2010;34(6):454-64.

27. Shonkoff JP, Garner AS, Committee on Psychosocial Aspects of C, Family H, Committee on Early Childhood A, Dependent C, et al. The lifelong effects of early childhood adversity and toxic stress. Pediatrics. 2012;129(1):e232-46.

28. Gopalkrishnan N. Cultural Diversity and Mental Health: Considerations for Policy and Practice. Frontiers in Public Health. 2018;6(179).

29. Nestor BA, Cheek SM, Liu RT. Ethnic and racial differences in mental health service utilization for suicidal ideation and behavior in a nationally representative sample of adolescents. Journal of affective disorders. 2016;202:197-202. 
1 30. Alcala HE, Balkrishnan R. Mental Health Services in Childhood: The Role of Family 2 Adversity. Public Health Rep. 2019;134(2):180-8.

3 31. Evans-Lacko S, Takizawa R, Brimblecombe N, King D, Knapp M, Maughan B, et al. 4 Childhood bullying victimization is associated with use of mental health services over five 5 decades: a longitudinal nationally representative cohort study. Psychological medicine. 6 2017;47(1):127-35.

7 32. Althouse BM, Allem J-P, Childers MA, Dredze M, Ayers JW. Population Health

8 Concerns During the United States\&\#x2019; Great Recession. American Journal of Preventive 9 Medicine. 2014;46(2):166-70.

10 33. Lorenc T, Lester S, Sutcliffe K, Stansfield C, Thomas J. Interventions to support people 11 exposed to adverse childhood experiences: systematic review of systematic reviews. BMC Public 12 Health. 2020;20(1):657. 


\section{Declarations}

\section{Ethics approval and consent to participate}

This study was reviewed by the Institutional Review Board, IRB B-Social/Behavioral Committee (IRB Registration \#00009620), of Augusta University and was deemed non-human subjects research.

\section{Consent for publication}

Not applicable

\section{Availability of data and materials}

The data used and analyzed are publicly available NLSY97 data from the U.S. Bureau of Labor Statistics at https://www.nlsinfo.org/. Restricted geocodes are available to approved investigators following the process and procedures described by the U.S. Bureau of Labor Statistics.

\section{Competing interests}

The authors declare that they have no competing interests. M.D.'s work on this manuscript was conducted as a paid consultant.

\section{Funding}

This study was funded by the U.S. Department of Health and Human Services, Health Resources and Services Administration, Maternal and Child Health Field Initiated Research Program via award R40MC32878. The funder did not play a role in the design, analysis, or interpretation or publication of this report.

\section{Authors' contributions}

TB conceptualized the design, obtained funding, analyzed data, drafted and revised the article. VH contributed to the design, funding, obtained and analyzed the data, and substantially revised the article. MD contributed to the funding, interpretation, and substantially revised the article. AT contributed to the interpretation and substantial revision of the article. All authors have read and approve of the final manuscipt as submitted.

\section{Acknowledgements}

Not applicable

\section{Authors' information (optional)}

Not applicable 